\title{
WEGENER GRANULOMATOSIS AS AN UNCOMMON CAUSE OF PANHYPOPITUITARISM IN CHILDHOOD
}

\section{Ozlem Kara1, Fatma Demirel ${ }^{1 *}$, Banu Celikel Acar², Nilgün Cakar ${ }^{2}$}

Ankara Child Disease Hematology and Oncology Training Hospital, Ankara, Turkey

${ }^{1}$ Department of Pediatric Endocrinology, ${ }^{2}$ Department of Pediatric Nephrology

\section{INTRODUCTION}

Wegener granulomatosis (WG) is a rare multisystem disorder, characterized by granulomatous, necrotizing small-vessel vasculitis. Although WG often involves respiratory tract and kidneys, it can also rarely involve the skin, mucosa, joints, eyes, nervous system and pituitary. Pituitary involvement is extremely rare and a total of 24 cases have been reported to date. Present case describes an adolescent patient who applied with panhypopituitarism symptoms and diagnosed with WG following assessments.

\section{CASE REPORT}

History: A female patient, aged 16 years, applied with fever, headache, severe generalized muscle and joint pain, polyuria and polydipsia. She was referred to our hospital because of the ongoing headache and deterioration of clinical status. The patient appeared weak, could barely talk, and was only able to walk with support.

\section{Physical examination}

Weight: $56 \mathrm{~kg}$ ( 25-50 p), height: $158 \mathrm{~cm}$ ( 10-25p)

BP: $95 / 60 \mathrm{mmHg}$, Heart beat: $102 / \mathrm{min}$,

Body temp: $38.6{ }^{\circ} \mathrm{C}$

Puberty: P5 T5 M1 (Amenorrhea during last two month)

\section{Laboratory}

WBC: $13300 / \mathrm{mm}^{3}, \mathrm{Hb}: 8.1 \mathrm{gr} / \mathrm{dl}$, MCV $68.7 \mathrm{fl}$, Platelet count: $359000 / \mathrm{mm}^{3}$

Urine density: 1002, urine culture: No growth

ESR: $\mathbf{8 0 ~ m m / h r ~ , ~ C R P : ~} \mathbf{1 6 . 6} \mathbf{~ m g / d l}$

ACTH $3.91 \mathrm{pg} / \mathrm{ml}$, Morning cortisol: $5.45 \mu \mathrm{g} / \mathrm{dl}$

$\mathrm{TSH} 0.10 \mu \mathrm{lU} / \mathrm{ml}$, sT4 $0,53 \mathbf{n g} / \mathrm{dl}$,

FSH $1.35 \mu \mathrm{lU} / \mathrm{ml}$, LH $0.43 \mu \mathrm{lU} / \mathrm{ml}$, E2 $13 \mu \mathrm{g} / \mathrm{ml}$,

IGF-1 48,9 ng/ml ( <-3 SDS)

IGF-BP3 1800 ng/ml_(<-3 SDS)

Prolactine $15.37 \mathrm{ng} / \mathrm{ml}$,

Amount of urine/24 hour: $8100 \mathrm{ml}$, serum osmolality: $292 \mathrm{mOsmol} / \mathrm{L}$, urine osmolality $93 \mathrm{mOsmol} / \mathrm{L}$
PITUITARY MRI

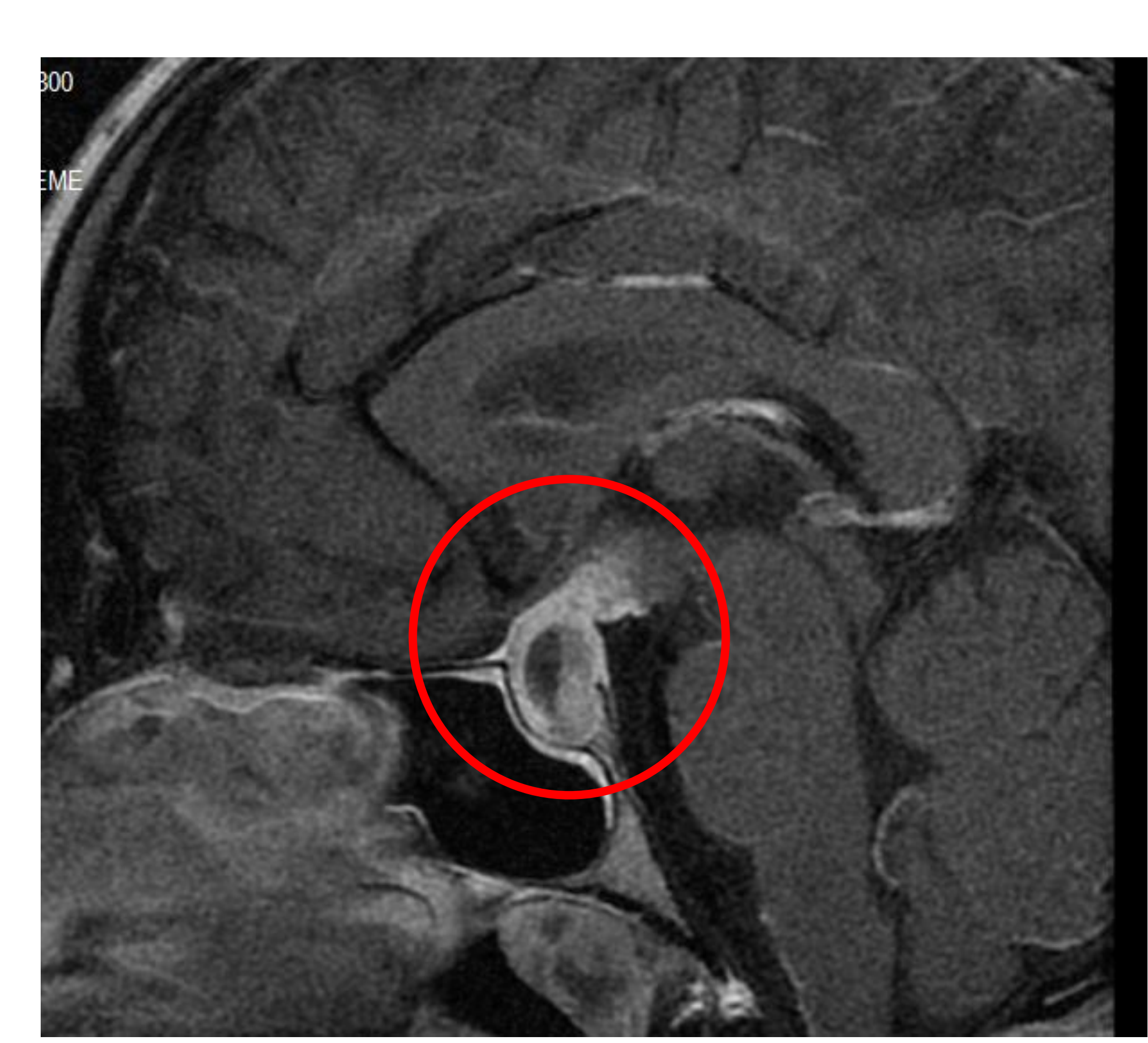

Figure 1.

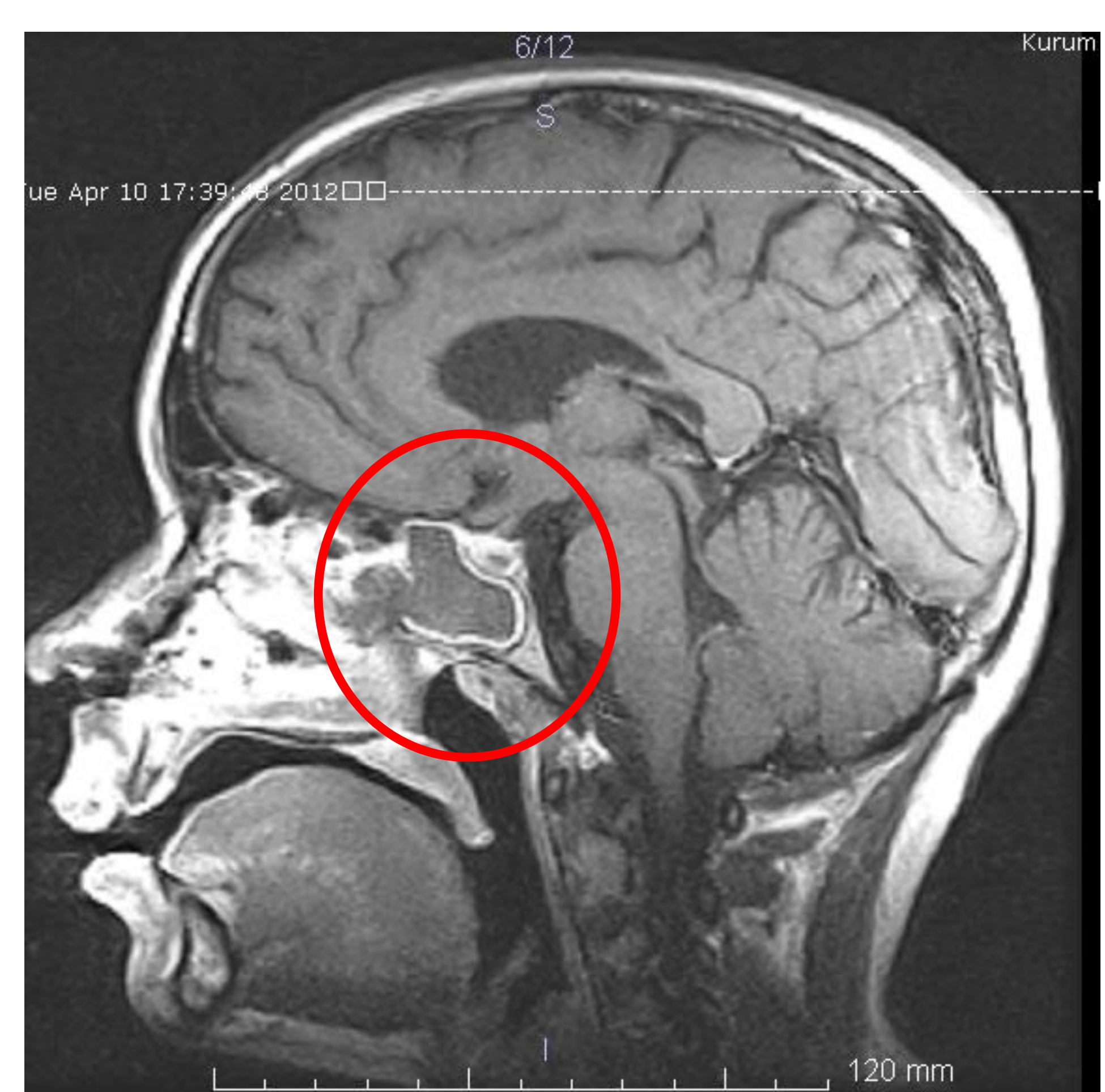

Figure 2.
Figure 1. High-signal-intensity mass, height of 15-19 $\mathrm{mm}$, suspicious necrotic hemorrhagic regions, and was pressing on the optic chiasm, thickening of the pituitary stalk, hypothalamic involvement, loss of the hyperintensity of the neurohypophysis, and inflammatory mucosal thickening in bilateral sphenoid sinuses

Figure 2. After steroid therapy regression of lesions in the hypophysis to $8 \mathrm{~mm}$, and considering the persistence of intense changes in signals in the paranasal sinus

\section{FOLLOW UP}

IV ampicillin-sulbactam, oral desmopressin, Na-Lthyroxine and glucocorticoid were started for panhypopituitarism. In the further assessments and analysis for diseases with granulomatous involvement of the pituitary gland, c-ANCA of $>\mathbf{2 0 0}$ $\mathbf{R U} / \mathbf{m L}$ (normal range $<20 \mathrm{RU} / \mathrm{ml}$ ) were determined. Microscopic hematuria, proteinuria, and pleural and pericardial effusion were observed while follow-up period. A renal biopsy was also performed to determine renal involvement, of which the results were consistent with WG. The patient was started on conventional glucocorticoid and cyclophosphamide treatment. The pituitary mass regressed to $6 \mathrm{~mm}$ at the end of the third month of treatment.

\section{CONCLUSION}

Wegener granulomatosis should be considered in patients with panhypopituitarism symptoms when suspected of a granulomatous disease due to the involvement of other organs. 